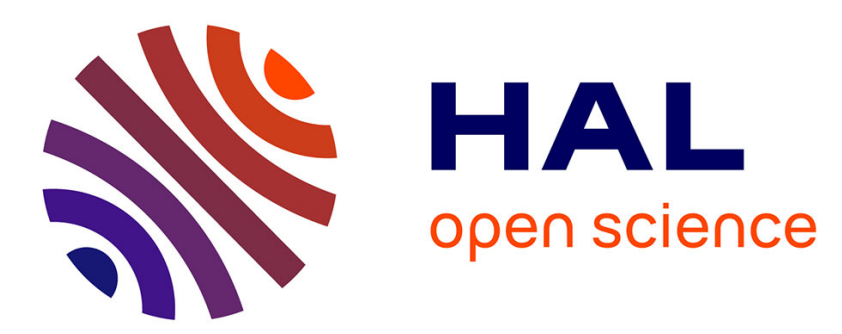

\title{
Predicting the flammability of polymers from their chemical structure: An improved model based on group contributions
}

Rodolphe Sonnier, Belkacem Otazaghine, Fadéla Iftene, Claire Negrell-Guirao, Ghislain David, Bob A. Howell

\section{To cite this version:}

Rodolphe Sonnier, Belkacem Otazaghine, Fadéla Iftene, Claire Negrell-Guirao, Ghislain David, et al.. Predicting the flammability of polymers from their chemical structure: An improved model based on group contributions. Polymer, 2016, 86, pp.42-55. 10.1016/j.polymer.2016.01.046 . hal-01266897

\section{HAL Id: hal-01266897 https://hal.science/hal-01266897}

Submitted on 25 Nov 2020

HAL is a multi-disciplinary open access archive for the deposit and dissemination of scientific research documents, whether they are published or not. The documents may come from teaching and research institutions in France or abroad, or from public or private research centers.
L'archive ouverte pluridisciplinaire HAL, est destinée au dépôt et à la diffusion de documents scientifiques de niveau recherche, publiés ou non, émanant des établissements d'enseignement et de recherche français ou étrangers, des laboratoires publics ou privés. 


\title{
Predicting the flammability of polymers from their chemical structure: An improved model based on group contributions
}

\author{
Rodolphe Sonnier $^{\mathrm{a}, *}$, Belkacem Otazaghine ${ }^{\mathrm{a}}$, Fadela Iftene ${ }^{\mathrm{b}}$, Claire Negrell ${ }^{\mathrm{b}}$, \\ Ghislain David ${ }^{\mathrm{b}}$, Bob A. Howell ${ }^{\mathrm{c}}$

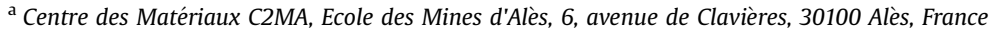 \\ b Institut Charles Gerhardt, Montpellier, UMR CNRS 5253, Equipe Ingénierie et Architectures Macromoléculaires, Ecole Nationale Supérieure de Chimie de \\ Montpellier, 8 rue de l'école normale, 34296 Montpellier Cedex 5, France \\ c Science of Advanced Materials, Center for Applications in Polymer Science, Department of Chemistry and Biochemistry, Central Michigan University, Mt. \\ Pleasant, MI 48859-0001, USA
}

\begin{abstract}
A B S T R A C T
A new method is proposed to calculate the flammability of polymers from their chemical structure using a Van Krevelen approach. The model is inspired from a pioneering work of Lyon which assigns one flammability contribution to each chemical group. The flammability property of the whole polymer is the sum of the contributions of chemical groups constituting the polymer. Two intrinsic properties (namely heat release capacity and total heat release) measured using pyrolysis-combustion flow calorimeter are correctly predicted for almost one hundred polymers containing contributions of only 31 chemical groups. The contributions of these groups are compared and the consistency of these values is discussed. Finally some exceptions, such as, phosphorus-containing polymers, are noted.
\end{abstract}

Keywords:

Polymer flammability

PCFC

Van Krevelen approach

\section{Introduction}

Improving the flame retardancy of polymeric materials can be achieved by incorporating flame retardant additives into the matrix. Another way is to synthesize inherently flame retardant polymers. This approach is assessed to be expensive because the flame retardancy of the polymer can be measured only after it has been synthesized. Of course some specific chemical functions are well known to impart flame retardancy, such as phosphorus-based moieties but generally a long trial and error approach is needed to reach a suitable flame retarded macromolecular structure.

It would be highly desirable to have a method allowing an accurate assessment of the flammability of a polymer structure before it is synthesized. The need for such method will increase because many biosourced compounds are being considered as new building blocks for innovative polymers [1-4].

One simple method proposed initially by Van Krevelen to predict many properties of materials is the additivity of groups [5]. Briefly, a polymer is divided in simple groups having specific

\footnotetext{
* Corresponding author

E-mail address: rodolphe.sonnier@mines-ales.fr (R. Sonnier).
}

contributions to the properties being studied. The overall property of the polymer is the sum of these contributions multiplied by the molar or weight fraction of the corresponding groups. Such an approach has been proposed for the calculation of some flammability properties of polymers as measured in PCFC [6].

The analysis is carried out under standard conditions, i.e. an anaerobic pyrolysis followed by a complete combustion of pyrolytic gases [6,7]. These properties are heat release capacity (HRC), char content and effective heat of combustion (EHC).

It is now well-known that PCFC is not suitable for assessment of the overall reaction-to-fire of a polymer. Some effects are not taken into account such as flame inhibition or a barrier effect [8]. Nevertheless, this method allows a first assessment of the fire performances and some approaches attempting to correlate statistically these performances to the rating in various other tests such as UL94 or some flame propagation tests $[9,10]$ have been reported.

Using the Van Krevelen method, a first database of the contributions of 38 groups has been proposed [6]. These contributions were calculated from an evaluation of flammability behavior of a set of 84 polymers. Pursuing this approach we attempted to calculate the contributions of two new groups: phosphonate and dioxaphosphorinane [11]. We showed that the Van Krevelen 
approach fails when these groups are present together with other groups such as carboxyls. In such molecules, phosphonate and carboxyl groups interact leading to experimental HRC values lower than calculated. Another attempt to predict the contributions of phosphonate group has been proposed [12].

However, it appears that the Lyon approach has not been widely used. One reason may be that the method used to calculate the contributions does not account for interactions which take place in some cases. Indeed for some polymers the additivity of group contributions is not suitable due to interactions between different groups of the structure. Such cases may result in inappropriate contributions. Moreover, the initial list of 38 groups contains those that were available rather than those expected to provide consistent results in contribution.

We propose an improved model based on the additivity of the contributions. The contributions of 31 groups have been determined from the flammability of a set of more than one hundred polymers. Moreover, the methodology used to build the model is presented and the consistency of results obtained illustrated. A few groups that do not yield consistent results are identified.

\section{Methodology}

\subsection{Measurements of THR and HRC}

Eqs. (1) and (2) explain how the total heat release (THR) and heat release capacity (HRC) of a polymer can be calculated from its structure.

$$
\begin{aligned}
& T H R=\sum_{i} w_{i} \times T H R_{i} \\
& H R C=\sum_{i} w_{i} \times H R C_{i}
\end{aligned}
$$

where $\mathrm{THR}_{\mathrm{i}}$ and $\mathrm{HRC}_{\mathrm{i}}$ reflect the contributions of the group $\mathrm{i}$ to THR and $\mathrm{HRC}$ respectively, and $\mathrm{w}_{\mathrm{i}}$ the weight fraction of the group $\mathrm{i}$ in the polymer.

The flammability of polymers (Table 1 ) was analyzed using PCFC (from FTT) under standard conditions, i.e. anaerobic pyrolysis from 25 to $750{ }^{\circ} \mathrm{C}$ at $1{ }^{\circ} \mathrm{C} / \mathrm{s}$ in nitrogen and complete combustion in an excess of oxygen at $900{ }^{\circ} \mathrm{C}$ [13].

The THR corresponds to the area under the heat release peak. The HRC generally corresponds to the peak of heat release rate (pHRR) divided by the heating rate. However, in some cases, several peaks can be observed. In such a case, sumHRC may be considered. SumHRC is the sum of the HRR peaks after deconvolution carried out using the FTT software. In some cases, the deconvolution is easy because the different peaks do not overlap. In other cases, several peaks overlap. When several peaks overlap, sumHRC was determined as previously described by summing the minimum number of Gaussian, Lorentzian, asymmetric Gaussian or Lorentzian, or asymmetric Gaussian-Lorentzian hybrid peaks needed to fit the HRR curve with an accuracy of at least 95\% [6]. Obviously the choice of the number of peaks influences the sumHRC.

The flammability of 107 polymers was assessed. They can be divided in three groups: commercial polymers tested in our lab, lab-made polymers also tested in our lab, and finally commercial or lab-made polymers analyzed by others [7,14-16]. Obviously in the latter case, we are not sure that the deconvolution method used to measure sumHRC is the same as ours.

\subsection{Deconstruction of a polymer containing several groups}

There are numerous possibilities for the deconstruction of a polymer structure containing several significant groups. For example, the Lyon approach includes the groups $-\mathrm{O}-$ and $-\mathrm{CH}_{2}-$ but also $-\mathrm{CH}_{2}-\mathrm{O}$ - and the contributions of the latter are not a linear combination of the contributions of the former [6]. It appears important to determine some guides to avoid redundancy as much as possible.

First, the carbon atom has different contributions according to the number of covalent bonds with $\mathrm{C}, \mathrm{H}, \mathrm{O}$ (or $\mathrm{OH}), \mathrm{N}, \mathrm{F}$ or $\mathrm{Cl}$ atoms. A double covalent bond is considered equivalent to a single covalent bond. So the $c=$ group is considered equivalent to the $-c$-group. Second, a series of groups is created by combination of an aromatic structure (including pyridine and naphthalene) with another group such as $-\mathrm{O}--\mathrm{CO}-\ldots$ Third, the contribution of an aromatic group depends on its position in the polymer (in the main chain or as pendant group). These three rules permit the generation of most of the groups to be considered. In addition, some special groups such as maleimide, maleic anhydride and phosphonate have also been created.

Nevertheless, these rules are not enough to avoid indecisions concerning the choice of groups constituting some polymers. For this study, poly(4-methoxystyrene) was dissected into four groups: $\mathrm{CH}_{2}, \mathrm{CH}$, phenyl and $-\mathrm{OCH}_{3}$. Another choice may have been $\mathrm{CH}_{2}$, $\mathrm{CH}$, phenyl-O- and $\mathrm{CH}_{3}$. Aromatic polyamide (numbered 34) was fragmented into $\mathrm{CH}_{2}$, phenyl-O and NHCO groups rather than $\mathrm{CH}_{2}$, phenyl-NHCO and $\mathrm{CH}_{2}-\mathrm{O}$ (Fig. 1). Another example is polycarbonate. Polycarbonate was deconstructed quite artificially into $\mathrm{C}, \mathrm{CH}_{3}$, phenyl-O and phenyl-OCO. We have preferred such deconstruction rather than the creation of a new group, phenylOCOO.

These examples show that arbitrary choices have been made in building the database. Much as earlier databases, this one is not complete and will evolve with the incorporation of data from the analysis of new polymers. Additional rules may be needed in the future. Nevertheless, the rules listed above provide a rationale for the construction of a reliable database.

\subsection{Model building "step-by-step"}

We showed in a previous study that the contributions of some groups depend on their environment. For example, we have observed that a phosphonate group has a rather high contribution to HRC in a series of simple molecules. However when the phosphonate group is present as well as acrylate or acrylic groups, the experimental HRC is systematically lower than the calculated one. We have assumed that this is due to interactions between these groups during the thermal degradation [11]. Indeed, it is well known that phosphorus is able to promote charring of polymers containing oxygen atoms.

Therefore if we consider all the polymers at the same time, the risk is the calculation of an average but meaningless contribution. We have preferred to build our model "step-by-step". An example of this method follows.

The first step consisted of the calculation of the contributions of some usual groups present in many polymers: $\mathrm{C}, \mathrm{CH}, \mathrm{CH}_{2}, \mathrm{CH}_{3}$, phenyl (pendant), $\mathrm{CH}_{2}-\mathrm{O}$ and $\mathrm{CH}_{3}-\mathrm{O}$ from a first series of 13 polymers containing only these groups (Fig. 2). Once the contributions of these groups were obtained, we calculated contributions of various fluorinated groups. Four groups were considered but three of them have the same contributions (Fig. 3). Contributions of the maleic anhydride group were calculated from a series of 10 polymers containing only groups for which the contributions had already been calculated. Poly(ethylene maleic anhydride) was not used for reasons discussed in a next section (Fig. 4). White points in Figs. 3 and 4 correspond to various polymers containing fluorinated or maleic anhydride groups but also other groups for which the 
Table 1

Polymers studied with their experimental and calculated THR and HRC.

\begin{tabular}{|c|c|c|c|c|c|c|}
\hline \multirow[t]{2}{*}{$\mathrm{N}^{\circ}$} & \multirow[t]{2}{*}{ Polymer } & \multirow[t]{2}{*}{ Remark } & \multicolumn{2}{|c|}{ Experimental value } & \multicolumn{2}{|c|}{ Calculated value $^{\mathrm{a}}$} \\
\hline & & & $\begin{array}{l}\text { THR }(\mathrm{kJ} / \\
\mathrm{g})\end{array}$ & $\begin{array}{l}\text { HRC }(\mathrm{J} / \\
\text { g.K) }\end{array}$ & $\begin{array}{l}\text { THR }(\mathrm{kJ} / \\
\mathrm{g})\end{array}$ & $\begin{array}{l}\text { HRC }(\mathrm{J} / \\
\text { g.K) }\end{array}$ \\
\hline 1 & Polyisoprene (IR) & Commercial & 40.2 & 753 & 39.0 & 749 \\
\hline 2 & Low density and High density polyethylene (PE) & Commercial & 41.3 & 1205 & 41.0 & 1200 \\
\hline 3 & Ethylene-octene copolymer ( $38.6 \mathrm{wt} \%$ octene) & Commercial & 41.8 & 1190 & 41.0 & 1152 \\
\hline 4 & Ethylene-octene copolymer ( 26.4 w\% octene) & Commercial & 40.5 & 1048 & 41.0 & 1155 \\
\hline 5 & Polypropylene (PP) & Commercial & 39.6 & 954 & 40.9 & 869 \\
\hline 6 & Polyisobutylene & Commercial & 44.4 & 1002 & 40.8 & 1007 \\
\hline 7 & Polybutadiene & Commercial & 38.7 & 643.5 & 38.6 & 574 \\
\hline 8 & Polymethylstyrene & Commercial & 35.8 & 740 & 37.4 & 897 \\
\hline 9 & Polymethoxystyrene & Commercial & 28.6 & 705 & 30.9 & 691 \\
\hline 10 & Polystyrene (PS) & Commercial & 35.6 & 849 & 35.9 & 815 \\
\hline 11 & Styrene-butadiene rubber ( $25 \mathrm{wt} \%$ styrene) & Commercial & 37.1 & 489 & 37.9 & 616 \\
\hline 12 & Poly(methylmethacrylate) & Commercial & 22.42 & 419 & 21.1 & 344 \\
\hline 13 & Polyacrylic acid & Commercial & 12.5 & 165 & 13.2 & 153 \\
\hline 14 & Polymethacrylic acid & Commercial & 18.4 & 464 & 17.7 & 359 \\
\hline 15 & Polyethylmethacrylate & Commercial & 26.6 & 425 & 23.5 & 449 \\
\hline 16 & Polyethylacrylate & Commercial & 22.6 & 323 & 21.2 & 313 \\
\hline 17 & Ethylene-butylacrylate copolymer (30wt\% butylacrylate) & Commercial & 36.4 & 770.5 & 36.3 & 992 \\
\hline 18 & Ethylene-methylacrylate (24wt\% methylacrylate) & Commercial & 36.3 & 848 & 35.5 & 952 \\
\hline 19 & Poly(dibutyl maleate - alt-1,1,1,2,2,3,3,4,4,5,5,6,6,7,7,8,8-heptadecafluoro-10-(vinyloxy)decane) & Our lab & 13.2 & 291 & 12.3 & 224 \\
\hline
\end{tabular}

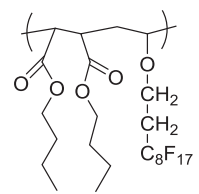

20 Polyvinylacetate

21 Ethylene-vinylacetate copolymer (9.3wt\% vinylacetate)

22 Ethylene-vinylacetate copolymer (15wt\% vinylacetate)

23 Ethylene-vinylacetate copolymer (26wt\% vinylacetate)

24 Ethylene-vinylacetate copolymer (28wt\% vinylacetate)

25 Polyamide 6

26 Polyamide 6-10

27 Polyamide 6-12

28 Polyamide $10-10$

29 Polyamide $10-12$

30 Polyamide 6-6

31 Polyamide 11

32 Polyamide 12

33 Polyamide 4-6

34 Polyamide: [(4,4'-(butane-1,4-diylbis(oxy))dianiline)- alt -(nonanedioic acid)]

35 Styrene-maleic anhydride copolymer (9wt\% maleic anhydride)

36 Styrene-maleic anhydride copolymer (26wt\% maleic anhydride)

37 Styrene-maleic anhydride copolymer (40wt\% maleic anhydride)

38 Poly(furan-2,5-dione - alt -1,1,1,2,2,3,3,4,4,5,5,6,6,7,7,8,8-heptadecafluoro-10-(vinyloxy)decane)<smiles>CC(CCCOC(C)C)CC1CC(=O)OC1=O</smiles><smiles>CCOC(C)CC1CC(=O)OC1=O</smiles>

40 Poly(3-methylenedihydrofuran-2,5-dione - alt -1-(vinyloxy)butane)<smiles>CCOC(I)CCC12CC(=O)OC1(C)C2(C)C</smiles>

41 Poly(3-methylenedihydrofuran-2,5-dione - alt -1,1,1,2,2,3,3,4,4,5,5,6,6,7,7,8,8-heptadecafluoro-10(vinyloxy)decane)

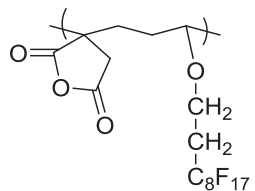


Table 1 (continued)

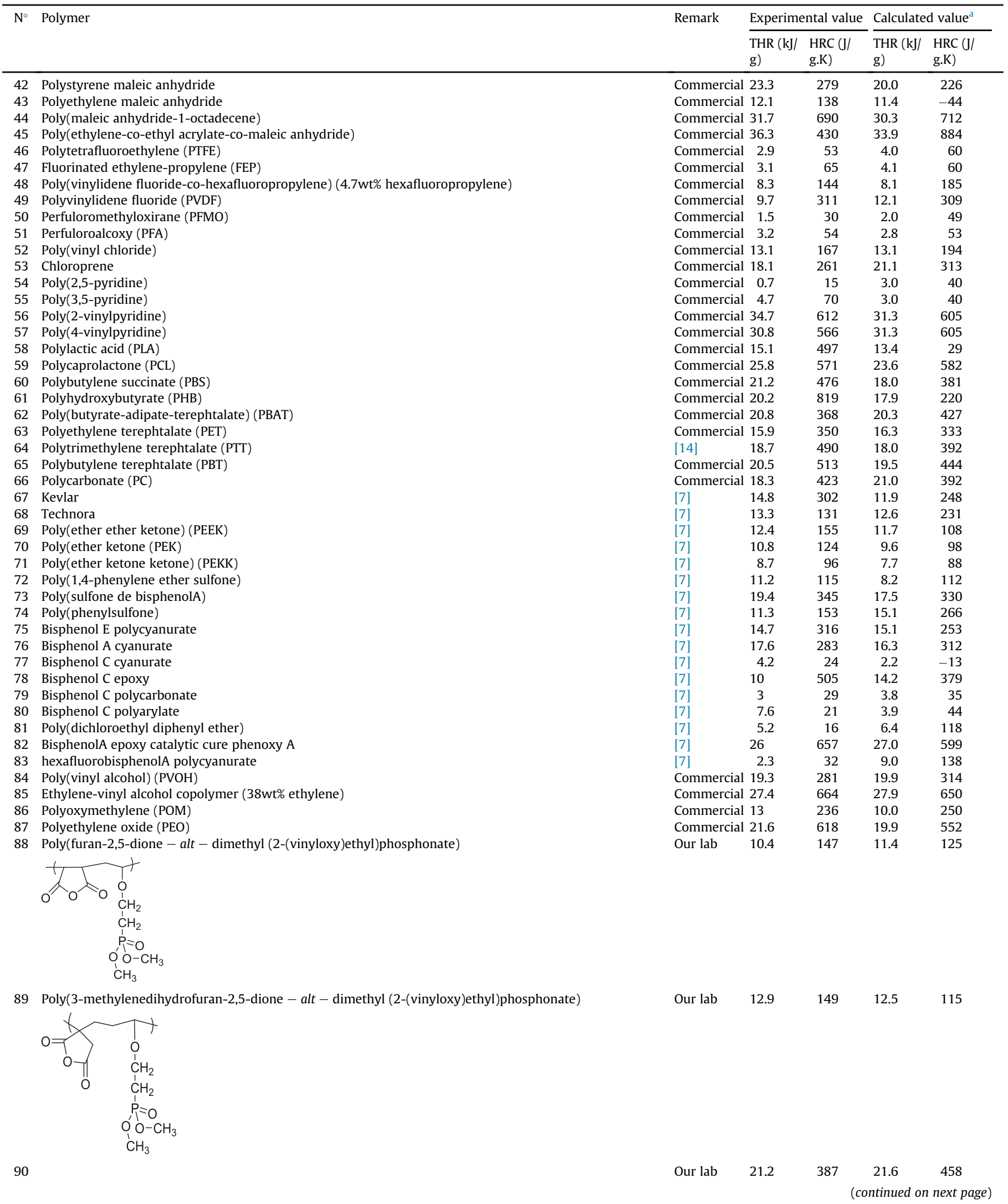


Poly(dibutyl maleate - alt - dimethyl (2-(vinyloxy)ethyl)phosphonate)

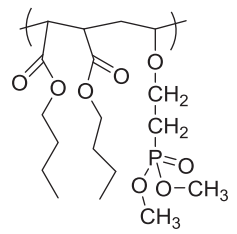

91 Poly(dibutyl 2-methylenesuccinate - alt - dimethyl (2-(vinyloxy)ethyl)phosphonate)

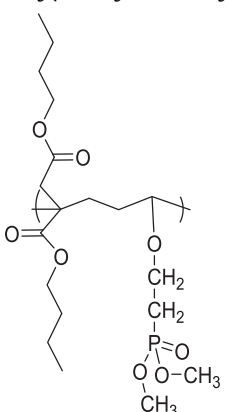

92 Poly(dimethyl(methacryloxy) methyl phosphonate)<smiles>CCC1(CC)CC1C(=O)OCCP(=O)(OC)OC</smiles>

93 Poly(vinylmethylphosphonate)<smiles>CCCC1CCCC1P(=O)(OC)OC</smiles>

94 Heptadecafluorodecyl-phosphonic acid

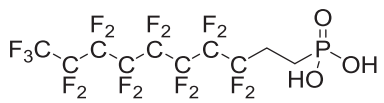

95 Poly(1-methyl-1H-pyrrole-2,5-dione - alt - dimethyl (2-(vinyloxy)ethyl)phosphonate)<smiles>COP(=O)(CCOC(C)CC1CC(=O)N(C)C1=O)OC</smiles>

96

Poly(1-butyl-1H-pyrrole-2,5-dione - alt - dimethyl (2-(vinyloxy)ethyl)phosphonate)<smiles>CCCCN1COP(=O)(OC)CCOC2CCCCC(C1=O)C(C)C2</smiles>

Our lab
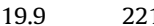

19.8

443

Our lab $\quad 11.6 \quad 246 \quad 12.3$ 229

Our lab 11.9 269 
Styrene-diethyl-(4-vinylbenzyl)phosphonate copolymer (5wt\% diethyl-(4-vinylbenzyl)phosphonate)

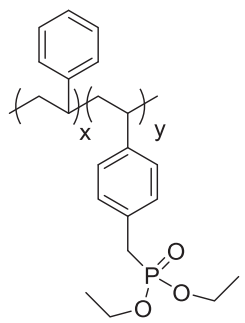

98 Styrene-diethyl-(4-vinylbenzyl)phosphonate copolymer (10wt\% diethyl-(4-vinylbenzyl)phosphonate)

99 Styrene-diethyl-(4-vinylbenzyl)phosphonate copolymer (20wt\% diethyl-(4-vinylbenzyl)phosphonate)

Our lab

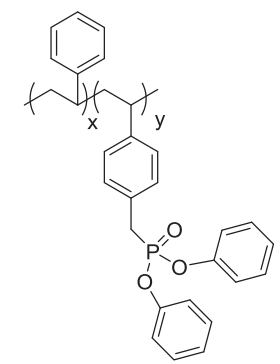

101 Poly(dimethyl-(4-vinylbenzyl)phosphonate) (HPM1) ${ }^{\mathrm{b}}$

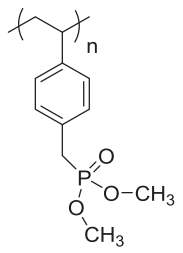

102 Poly(diethyl-(4-vinylbenzyl)phosphonate) (HPM2)

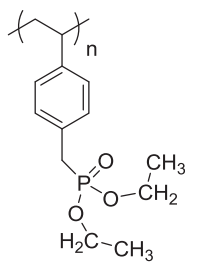

103 Poly(diphenyl-(4-vinylbenzyl)phosphonate) (HPM3) ${ }^{b}$

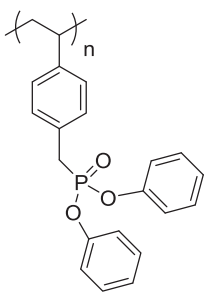

104 Poly(1-methyl-1H-pyrrole-2,5-dione - alt -1,1,1,2,2,3,3,4,4,5,5,6,6,7,7,8,8-heptadecafluoro-10-(vinyloxy) decane)

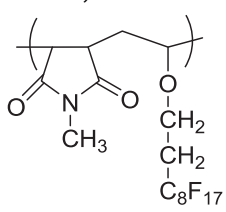

105 Poly(1-butyl-1H-pyrrole-2,5-dione - alt -1,1,1,2,2,3,3,4,4,5,5,6,6,7,7,8,8-heptadecafluoro-10-(vinyloxy) decane) 


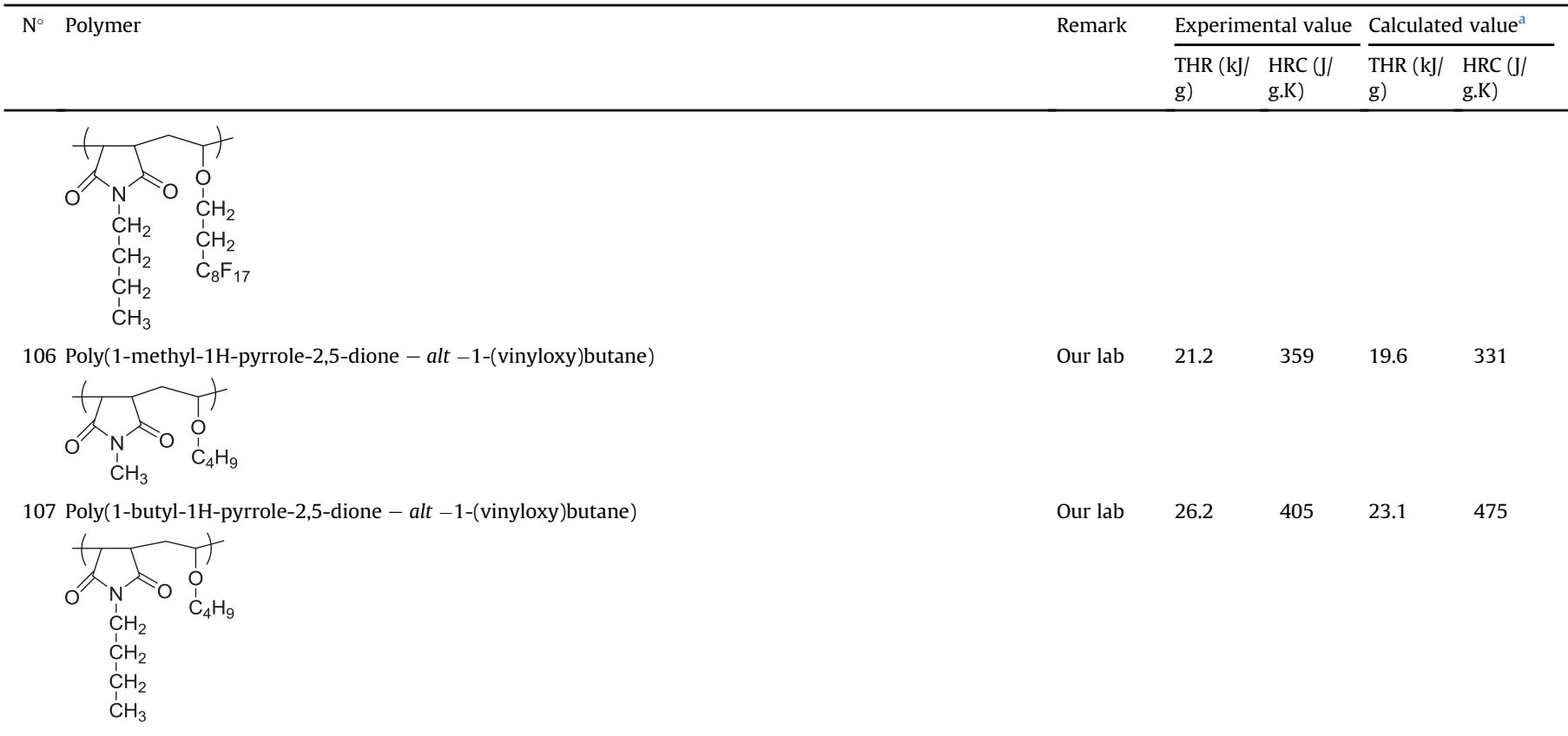

\footnotetext{
a Using database 1.

b SumHRC graphically estimated from the curves in Ref. [16].
}

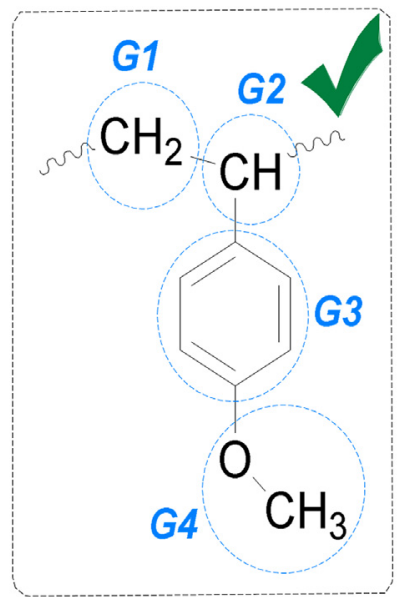

\section{Structure fragmentation used}

Fig. 1. Example of two possible structure fragmentations for poly(4-methoxystyrene).

contributions to HRC were calculated later. These polymers were not used for the calculation of contributions of fluorinated or maleic anhydride groups but they can be used to generate control data.

If the contributions of some groups (as fluorinated or maleic anhydride groups) were calculated with a good accuracy, it is not the case of some other groups such as maleimide. Only four polymers were used to assess the contributions of the maleimide group (Fig. 5). Two polymers also contain a phosphonate group and were not used for this calculation because the contributions of phosphonate group had not yet been evaluated (white points). Further analyses including data from additional polymers are needed to improve the accuracy of these calculated contributions.

In Lyon's work, 38 group increments were used to predict the flammability of 84 lab-made or commercial polymers [6]. In this

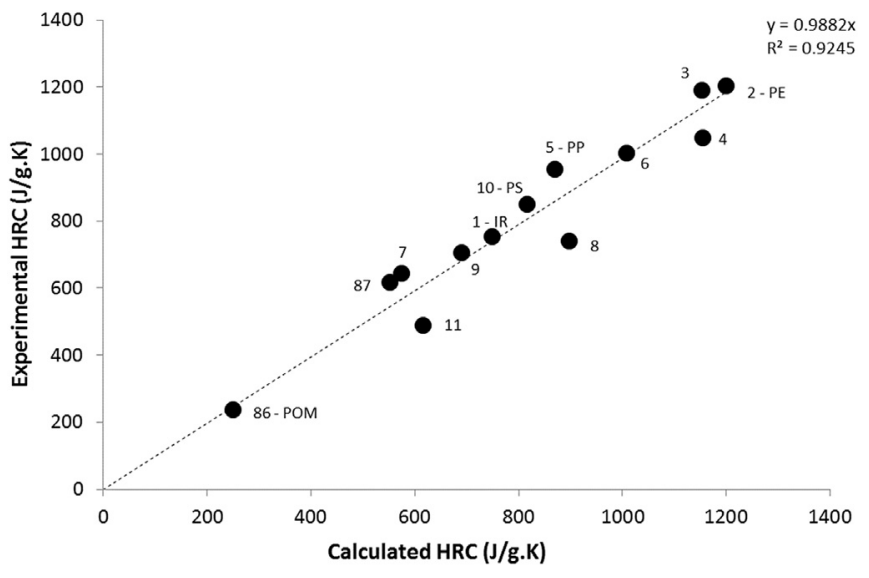

Fig. 2. Experimental versus calculated HRC for a first series of polymers (labels correspond to polymers numbered in Table 1).

study, 107 polymers and 31 groups were considered. We have also proposed an alternative database for the contributions to THR. In this second database, some groups are combined (for example, $\mathrm{C}$, $\mathrm{CH}, \mathrm{CH}_{2}$ and $\mathrm{CH}_{3}$ ) but without reducing substantially the accuracy of the calculations. Only 15 groups were considered to predict correctly the THR of all polymers studied.

All groups including their contributions to THR an HRC are listed in Table 2.

\section{Results and discussion}

All polymers including experimental and calculated THR and HRC are listed in Table 1. Figs. 6 and 7 show the correlation between experimental and calculated THR and HRC respectively for all the polymers tested.

An error value noted $E$ for the predicted THR is calculated as follows: 


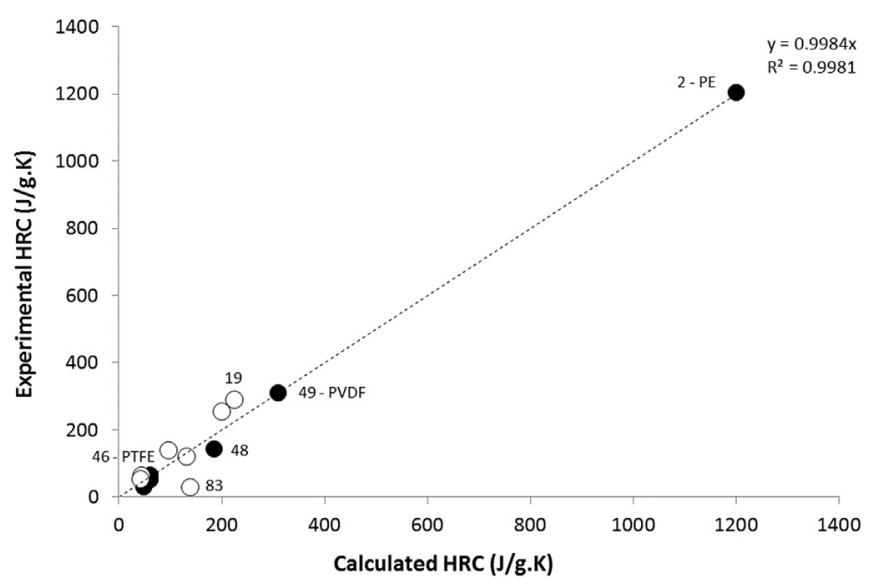

Fig. 3. Experimental versus calculated HRC for fluorinated polymers (labels correspond to polymers numbered in Table 1).

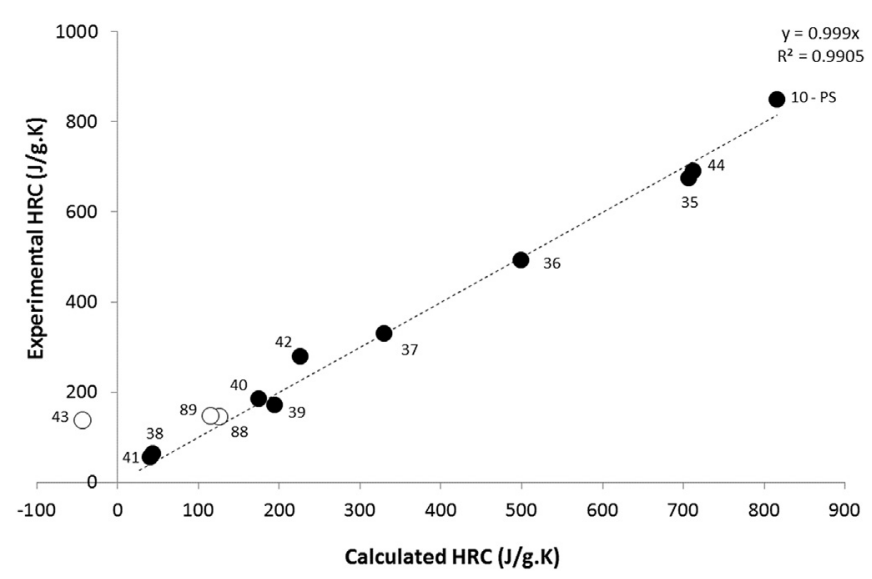

Fig. 4. Experimental versus calculated HRC for polymers containing a maleic anhydride group (labels correspond to polymers numbered in Table 1).

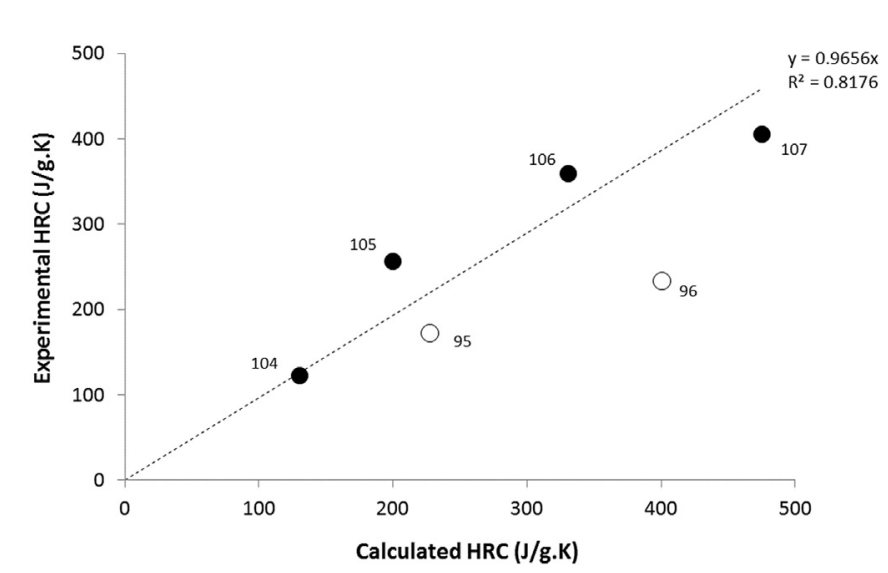

Fig. 5. Experimental versus calculated HRC for polymers containing a maleimide group (labels correspond to polymers numbered in Table 1).

$E($ in $\%)=\frac{100 \times\left|T H R_{\exp }-T H R_{\text {calc }}\right|}{T H R_{\exp }}$

$\mathrm{THR}_{\text {exp }} \mathrm{P}$ and $\mathrm{THR}_{\mathrm{cal}} \mathrm{C}$ are the experimental and calculated THR respectively. The error value for the predicted HRC is calculated similarly. The mean error for THR is lower than $16 \%$. The mean error for HRC (excluding 8 exceptions which will be discussed later) is $28 \%$. Considering only polymers exhibiting an experimental HRC higher than $200 \mathrm{~J} / \mathrm{g} . \mathrm{K}$, the mean error decreases to $11 \%$.

\subsection{Contribution to THR: a comparison with the Huggett relation}

THR depends on the char fraction $\mu$ and the EHC (energy released by complete pyrolysis and combustion of the polymer) according to the Eq. (4).

$E H C=T H R+\mu \times E H C_{\text {char }}$

With $E H C_{\text {char }}$ the energy released by the complete pyrolysis and combustion of the char.

EHC values for the various groups studied in this work can be calculated using the Huggett relation [17]. This relation considers that $1 \mathrm{~kg}$ of oxygen consumed during the combustion corresponds to an energy release of $13.1 \mathrm{MJ}$, whatever the molecular structure of the polymer.

The contributions to THR for various groups versus the corresponding EHC are plotted in Fig. 8. A very good correlation can be found between both values for the majority of the groups. This means that these groups are fully decomposed into gases during degradation and do not leave char.

On the contrary, few groups exhibit contributions to THR much lower than the calculated EHC. These groups can promote char formation during degradation, or can induce charring by other groups present in the polymer. This is particularly the case for the phenyl-CO- group, which is present in charring polymers as PEEK, PEK, PEKK and bisphenol $C$ polyarylate. These four polymers exhibit char contents of 46.5, 52.9, 60.7, $42.7 \mathrm{wt} \%$ [6].

Walters et al. have shown that the char composition is close to $\mathrm{C}_{5} \mathrm{H}_{2}$ in most cases [18]. The energy released by the complete pyrolysis and combustion of such char is then $37.2 \mathrm{~kJ} / \mathrm{g}$. When the contribution to THR is significantly different from EHC calculated using Huggett's relation, it would be possible to calculate the contribution to char according to Eq. (5).

$\mu=\frac{E H C-T H R}{E H C_{\text {char }}}$

As an example, the contributions to char of two groups Phenyl-O and Phenyl-CO - have been calculated using Eq. (5): 0.37 and 0.71 respectively. Then the char fractions of PEEK, PEK and PEKK have been calculated using these contributions: 48.9, 54.6 and $60.1 \mathrm{wt} \%$. The agreement between these calculated and the experimental char fractions is very good.

A last case corresponds to the $\mathrm{CCl}_{2}$ group whose contribution to THR is very low. This group contains two halogen (chlorine) atoms which are well known as effective flame inhibitors. It has previously been shown that some molecules containing bromine (for example poly(4-bromostyrene (PS-Br)) are not fully oxidized in PCFC under standard conditions [19]. Therefore the low contribution to THR of this group may also be due to incomplete combustion, i.e. the observed value is lower than the value calculated according to the Huggett relation.

\subsection{What is the meaning of negative or low contribution to HRC?}

A negative contribution to HRC means that the group considered is able to decrease the degradation rate of other groups present in the macromolecular structure. It is quite probable that low contributions to THR and to HRC are quite well correlated. But a high contribution to THR does not mean systematically a high 
Table 2

Chemical groups and their contributions.

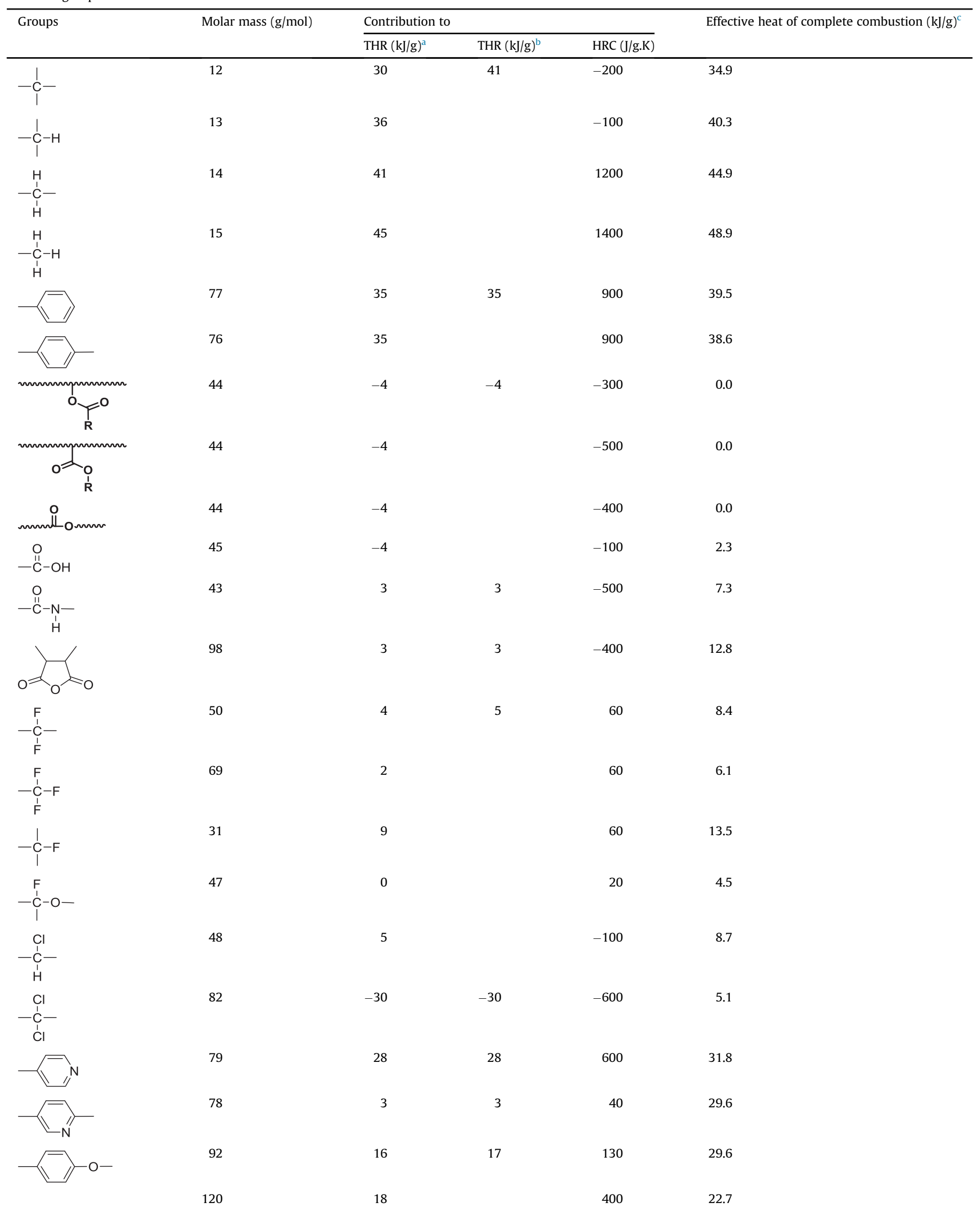




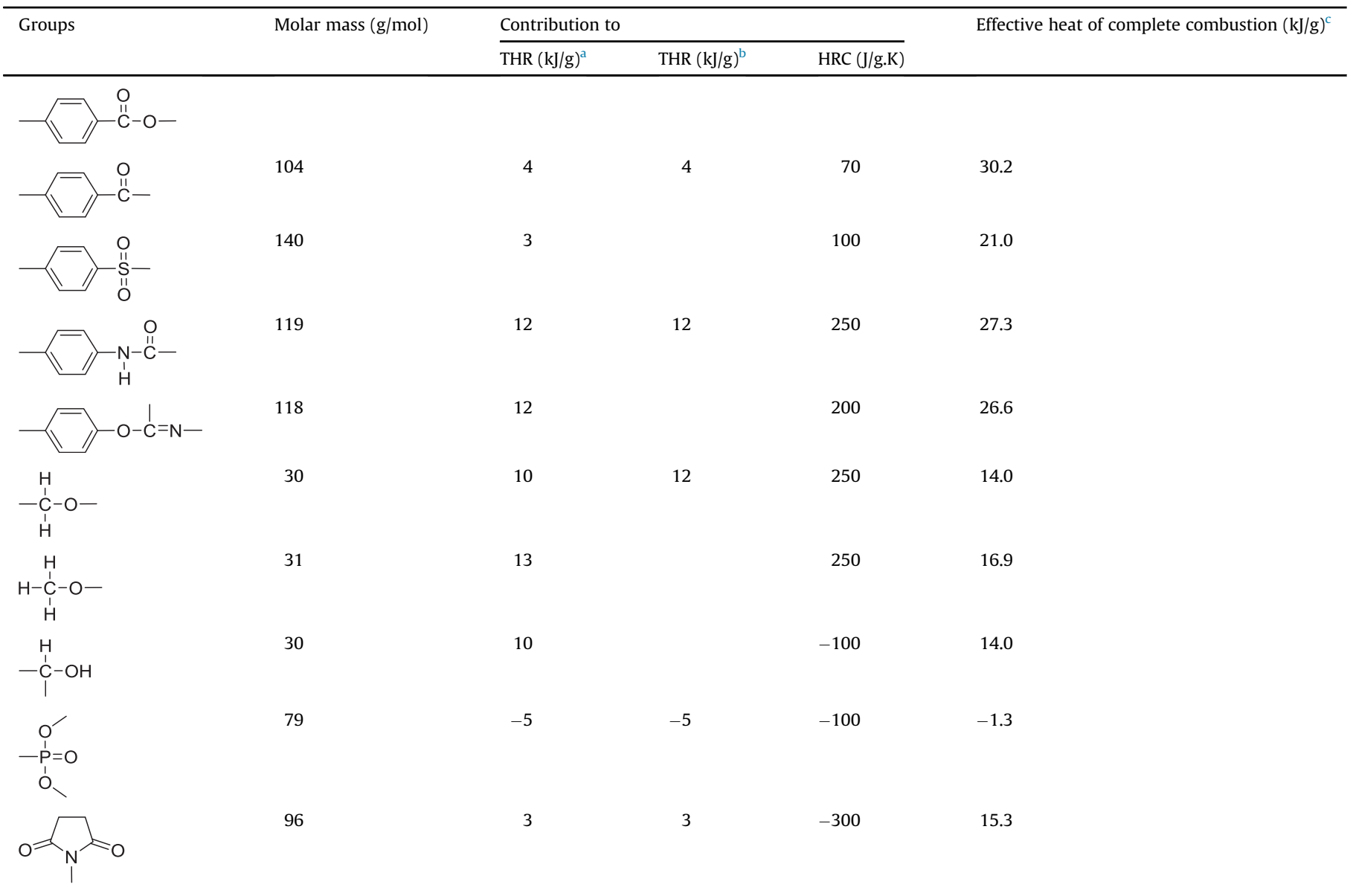

a First database.

b Second database.

c From Huggett's relation [17].

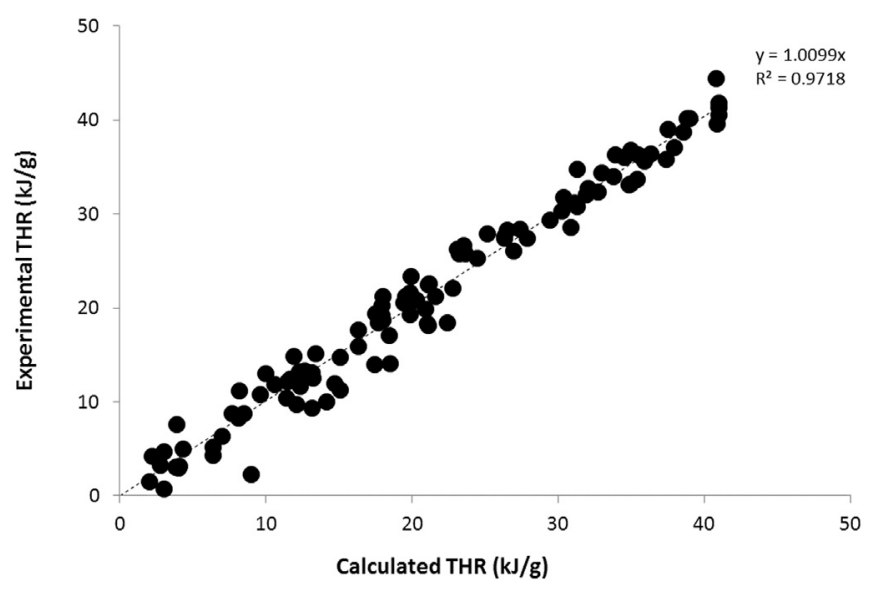

Fig. 6. Experimental versus calculated THR for 107 polymers studied in this work (using first database).

contribution to HRC. Both contributions for all considered groups are plotted in Fig. 9.

It can be observed that most generally contributions to THR and HRC are correlated. But there are few interesting exceptions. Especially $\mathrm{C}$ and $\mathrm{CH}$ exhibit both high contributions to THR but negative contributions to HRC. This is dramatically different from

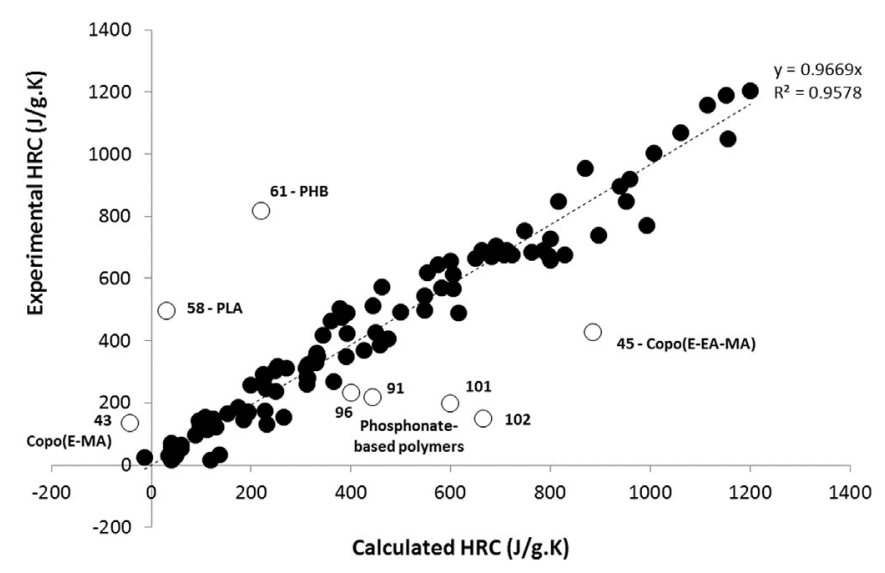

Fig. 7. Experimental versus calculated HRC for 107 polymers studied in this work (dashed line was plotted considering only black points - white points correspond to exceptions discussed later).

the behavior of $\mathrm{CH}_{2}$ and $\mathrm{CH}_{3}$ which exhibit similar contributions to THR but also very high contributions to HRC. Increasing the unsaturations or the pendant groups (i.e. increasing the degree of oxidation of carbon atoms) along the main chain of a macromolecule generally decreases the HRC. Nevertheless, most of pendant groups (such as phenyl) can also increase the HRC. 


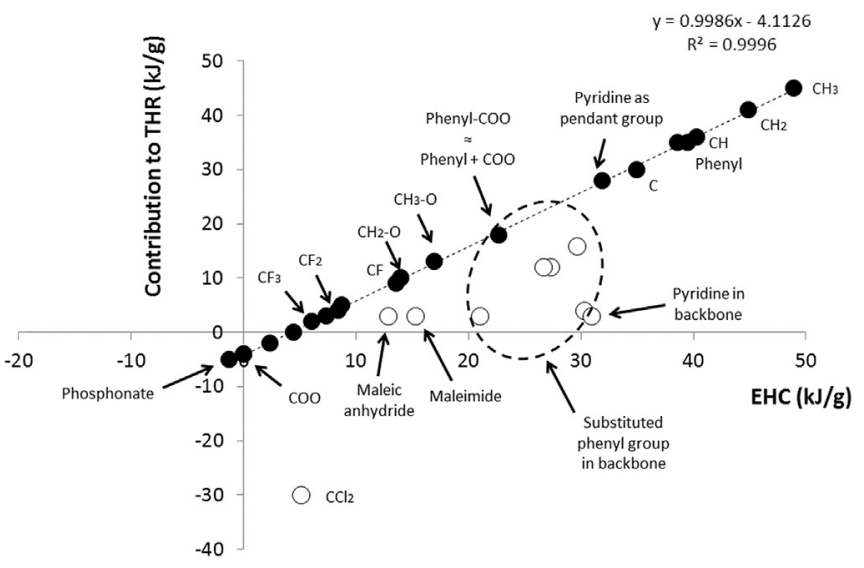

Fig. 8. Contribution to THR versus EHC calculated from the Huggett relation.

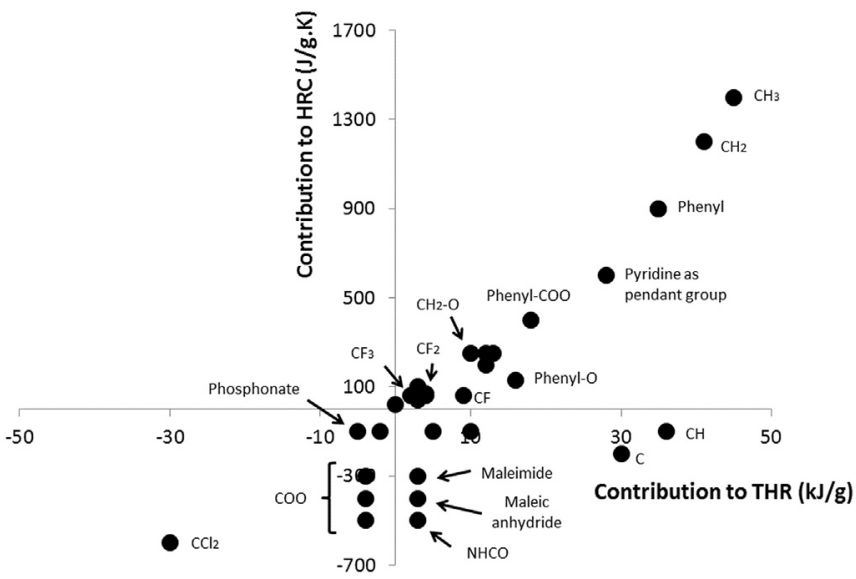

Fig. 9. Contribution to HRC versus contribution to THR for 31 groups.

Some other groups exhibit negative contributions to HRC: COO (acetate, acrylate, ester, carboxylic acid), maleimide, maleic anhydride, amide, chlorinated groups and finally phosphonate. All these groups contain carbon or phosphorus atoms for which the degree of oxidation is high.

Among the aromatic groups, the correlation between the contributions to THR and HRC is generally good (Fig. 10). This means that a group releasing little energy (due to charring) also exhibits a low rate of degradation (a low HRC). Only the phenyl-O group exhibits a low contribution to HRC with respect to its contribution to THR.

Finally all groups can be divided into three sets. The first one includes the groups exhibiting well correlated contributions to THR and to HRC (for example $\mathrm{CH}_{2}$, phenyl, $\mathrm{CF}_{2}$ ). The second set includes the groups exhibiting non-correlated contributions to THR and to HRC (for example, $\mathrm{CH}, \mathrm{NHCO}$...). The third set is constituted by only one group: phosphonate, for which the contribution to HRC is quite arbitrary and is not constant for all phosphonate-based polymers. This specific case will be discussed later.

\subsection{Consistency of the model}

Even if the model needs to be adjusted further, it must provide consistent results, i.e. the contributions calculated must be meaningful. It appears that the contribution to HRC of $\mathrm{C}, \mathrm{CH}, \mathrm{CH}_{2}, \mathrm{CH}_{3}$ increases with the number of hydrogen atoms bonded to the carbon, i.e. when the degree of oxidation of the carbon atom decreases.

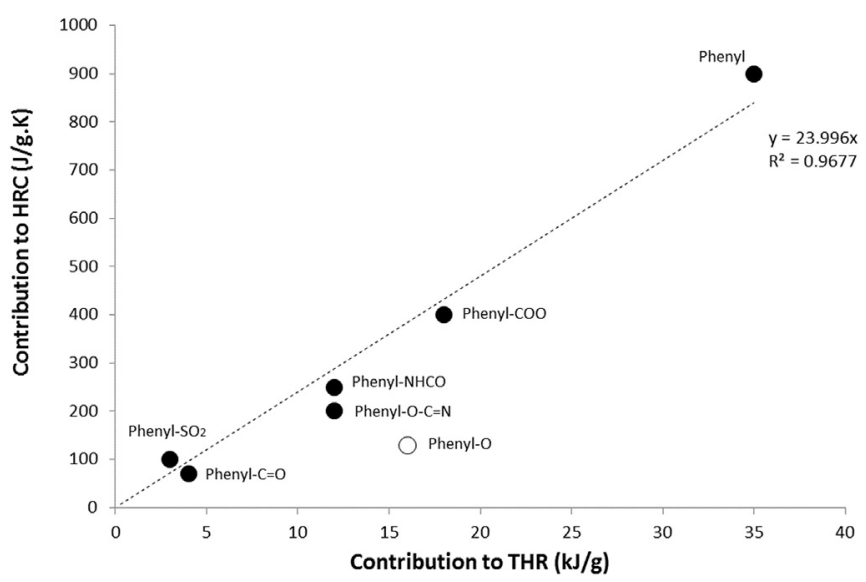

Fig. 10. Contribution to HRC versus contribution to THR for phenyl groups in backbone.

This result, consistent with earlier projections, would appear to be quite reasonable. Indeed, to a first approximation, the rate of heat release (or the rate of mass loss) depends on the nature and the number of bonds to be broken and the number of $\mathrm{C}=\mathrm{O}$ bonds to be formed in order to obtain a fully oxidized species.

Similarly, the contribution to HRC must be lower (or at least equal) when a group is present in the main chain rather than as pendant group. This is particularly the case for the pyridine group. As a pendant group, it exhibits high contributions to THR $(28 \mathrm{~kJ} / \mathrm{g})$ and to HRC (600 J/g.K). On the contrary, poly(2,5-pyridine) and poly(3,5-pyridine) lead to very high char fraction (more than 0.75 for poly(2,5-pyridine)). Therefore the contributions to THR and HRC of a pyridine group in the main chain are $3 \mathrm{~kJ} / \mathrm{g}$ and $40 \mathrm{~J} / \mathrm{g} . \mathrm{K}$ respectively. It is also noteworthy that no strong difference was observed between poly(2,5-pyridine) and poly(3,5-pyridine) or between poly(2-vinylpyridine) and poly(4-vinylpyridine).

It is interesting to note that the electronic structure of polymers may be dramatically different despite of the presence of the same groups. Indeed, when pyridine is present in the main chain, electrons are relocated on the whole chain (conjugated structure). Such a structure explains why such polymers are electron conductive. This is not the case when pyridine is present as pendant group.

In contrast to the pyridine group, the phenyl group does not exhibit different contributions as pendant or main chain constituent. The contributions to THR and to HRC are high: $35 \mathrm{~kJ} / \mathrm{g}$ and $900 \mathrm{~J} / \mathrm{g} . \mathrm{K}$ respectively. The phenyl group is present as a pendant group in polystyrene and derivatives (poly(4-methylstyrene) ...). These polymers exhibit high THR and HRC. In contrast to pyridinecontaining polymers, polymers containing phenyl in the main chain do not exhibit a delocalization of electron density along on the whole chain.

In this model, the phenyl group in the main chain is also associated with other groups such as $\mathrm{CO}, \mathrm{COO}, \mathrm{SO}_{2} \ldots$ in specific arrangements. One interesting case concerns the group phenyl-COO. The contributions of this group are very close to the sum of contributions of phenyl and COO groups: $18 \mathrm{~kJ} / \mathrm{g}$ and $400 \mathrm{~J} / \mathrm{g} . \mathrm{K}$ versus $20.7 \mathrm{~kJ} / \mathrm{g}$ and $387 \mathrm{~J} / \mathrm{g} . \mathrm{K}$. Therefore including this group phenyl-COO may be optional. Nevertheless, such a case is not general (see the case of phenyl-NHCO group in the following).

The contributions of various phenyl groups ( 7 groups) were calculated for a series of 22 polymers (mainly obtained from the Lyon database [7]). Considering that most of these polymers exhibit low THR and HRC and high char content, the correlation between experimental and calculated contributions is quite satisfying (Fig. 11). 
The contributions of these groups are listed in Fig. 12. All these groups exhibit significantly lower contributions than does the phenyl group when included in the main chain. It appears that the lowest contributions may be assigned to phenyl- $\mathrm{SO}_{2}$ (present in polysulfone polymers) and phenyl- $\mathrm{C}=\mathrm{O}$ (present in PEEK and derivatives). Phenyl-O exhibits moderate contribution to THR but low contribution to HRC. Moderate contributions are assigned to phenyl-COO, phenyl-NHCO and phenyl $-\mathrm{O}-\mathrm{C}=\mathrm{N}$. As already noted the contributions of phenyl-COO are similar to the sum of the contributions of phenyl and COO. It is not the case for phenylNHCO. The contributions of this group are significantly lower than the sum of the contributions of phenyl and NHCO: respectively $12 \mathrm{~kJ} / \mathrm{g}$ and $250 \mathrm{~J} / \mathrm{g} . \mathrm{K}$ versus $23.4 \mathrm{~kJ} / \mathrm{g}$ and $394 \mathrm{~J} / \mathrm{g} . \mathrm{K}$. This means that phenyl bonded to NHCO in the main chain improves the flame retardancy of a polymer. These groups interact synergistically.

\subsection{Exceptions to the model}

As already mentioned this model (and all models based on additive contributions) is simplistic and approximate. It may be possible to add contributions corresponding to the interactions between groups but it would result in many contributions, potentially more contributions than polymers.

Therefore there are a few exceptions, i.e. some polymers for which the experimental THR or HRC do not correspond to the calculated ones. The model will be really interesting only if it is able to explain these exceptions or at least to provide new insights about them.

As observed above, there may be only one exception concerning THR: hexafluorobisphenolA polycyanurate exhibits an experimental THR lower than the calculated one. The THR of all other polymers can be calculated with quite good accuracy. On the contrary, there are few but significant exceptions concerning HRC.

Obviously some uninteresting exceptions are due to the additivity character of the model: for example, poly(ethylene-maleic anhydride) exhibits a negative HRC. It is the only polymer containing maleic anhydride for which the calculated HRC does not fit well the experimental one. It is also the simplest structure among these polymers. In this copolymer, the contribution of two methylene groups $\left(\mathrm{CH}_{2}\right)$ is too low to compensate the negative contribution of the weighty maleic anhydride. Therefore the contributions calculated in this work may be suitable only when the weight fraction of the group considered is not too high.

Another exception concerns two aliphatic polyesters: PLA and PHB. Both exhibit an experimental HRC much higher than the

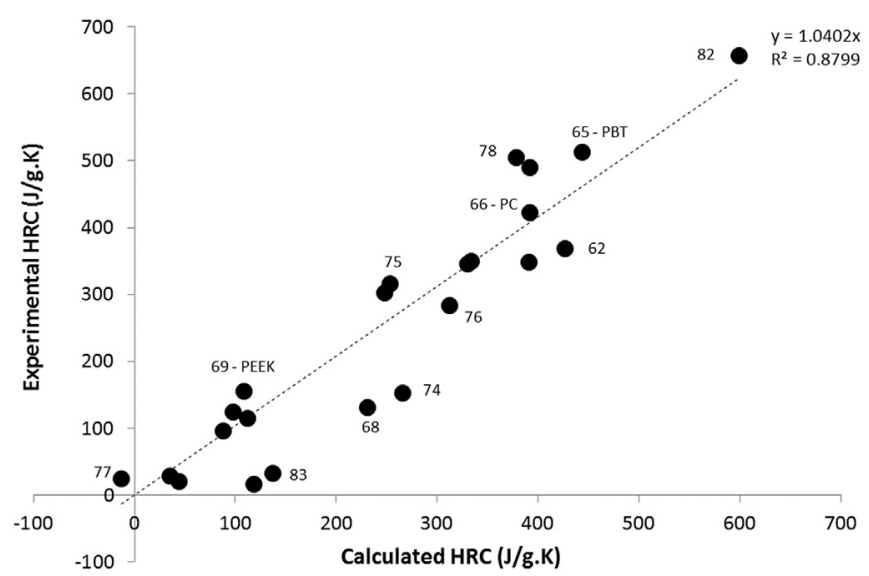

Fig. 11. Experimental versus calculated HRC for polymers containing various phenyl groups in the main chain (labels correspond to polymers numbered in Table 1).

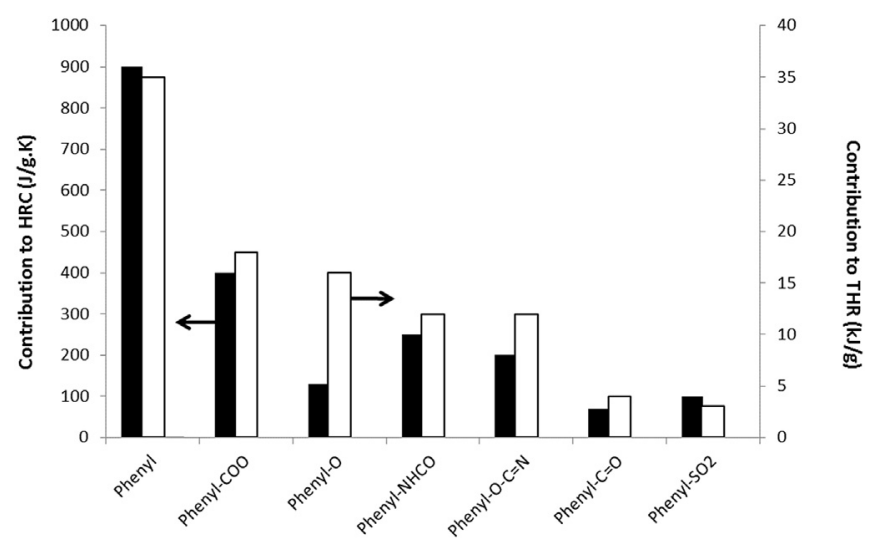

Fig. 12. - Contributions to THR and HRC for various substituted phenyl groups in the polymer main chain.

calculated ones. The difference between experimental and calculated values is at least $500 \mathrm{~J} / \mathrm{g} . \mathrm{K}$ in both cases. It must be noticed that both PLA and PHB have a similar structure, with a methyl group in the alpha position with respect to the oxygen atom of the ester group: $\mathrm{COO}-\mathrm{CH}-\mathrm{CH}_{3}$. The model suggests that the specific location of the methyl group destabilizes the ester function leading to a very high degradation rate and then to a high HRC. This finding is also supported by the low degradation temperature of these two polymers: pHRR is observed at 310 and $390{ }^{\circ} \mathrm{C}$ respectively for $\mathrm{PHB}$ and PLA, in comparison to $410-430{ }^{\circ} \mathrm{C}$ for other polyesters, and even $450{ }^{\circ} \mathrm{C}$ for PET.

Another exception concerns a copolymer (ethylene-co-ethyl acrylate-co-maleic anhydride) but the content of maleic anhydride is quite negligible ( $2 \mathrm{wt} \%$ ). The reason for this exception is not understood and needs more exploration.

The main exception corresponds to various polymers containing phosphonate groups. Indeed, phosphorus is a well-known charring promoter and its efficiency depends on its environment. It has previously been observed that the contributions of a phosphonate group calculated using a first series of molecules was not satisfactory for those also containing COO groups [11]. In such molecules, the experimental HRC was systematically lower than the calculated value. The highest deviation was observed when the ratio $\mathrm{COO} /$ phosphonate was equal to 2 .

It is possible to calculate a contribution to THR for the phosphonate group which is satisfactory for all 16 phosphonate-based polymers (see Fig. 13). This means that in these polymers, phosphonate is unable to promote the formation of a thermally stable char. If the phosphonate group is only present as a pendant group in these polymers, its location may limit its ability to promote charring.

Nevertheless, it is not possible to choose a contribution to HRC that is satisfactory for all polymers considered. It may be assumed that in some polymers, the phosphonate group can interact with other groups present in the macromolecule, leading to a low HRC. But in other polymers, it can be expected that no interaction occurs and then it would be possible to calculate properly the contributions of the phosphonate group. Such a possibility would be particularly interesting because it would be possible to identify the structures in which phosphonate interacts with its environment by comparison between the calculated and experimental HRC.

There are several methods for approaching the calculations of the contributions of the phosphonate group. All of them are somewhat arbitrary. A first method is to choose the contribution to HRC of phosphonate group so that calculated HRC of polymers are systematically higher or equal to the experimental ones. Another 


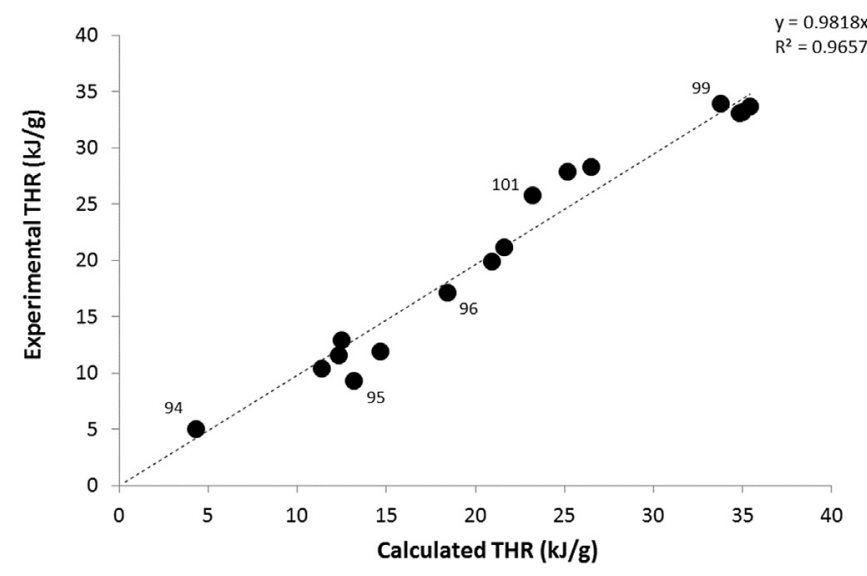

Fig. 13. Experimental versus calculated THR for 16 phosphonate-based polymers (labels correspond to polymers numbered in Table 1).

method (followed in this work) is to choose the contribution to HRC from the contribution to THR according to the tendency observed in Fig. 9. Indeed, a quite good correlation is found between the contributions to HRC and to THR for most of groups. For a contribution to THR close to $-5 \mathrm{~kJ} / \mathrm{g}$ as for phosphonate group, the contribution to HRC should be around $-100 \mathrm{~J} / \mathrm{g} . \mathrm{K}$. It is noteworthy that this value is also in agreement with the first method proposed above: all experimental HRC are lower or equal (but never higher) than the calculated values.

The experimental versus calculated HRC values for the 16 polymers considered using a contribution to HRC equal to $-100 \mathrm{~J} /$ g.K for the phosphonate group are plotted in Fig. 14. It can be observed that a good correlation between both values is found for about 12 polymers. None of these 16 polymers exhibit experimental HRC much higher than the calculated ones. On the contrary four polymers exhibit experimental HRC significantly lower than calculated ones (91, 96, 101 and 102). A very interesting observation may be noted for two of them: HPM1 (101), HPM2 (102). They have a structure similar to HPM3 (103). Only the groups bonded to the phosphonate group change: methyl, ethyl or phenyl. The calculated HRC of the three polymers are close to $600 \mathrm{~J} /$ g.K. While HPM1 and HPM2 exhibit much lower experimental HRC, HPM3 (phenyl groups bonded to the phosphonate group) has an experimental HRC much higher and close to the calculated one. The phenyl groups may inhibit the efficiency of the phosphonate group to reduce the heat release rate through interactions with the chemical

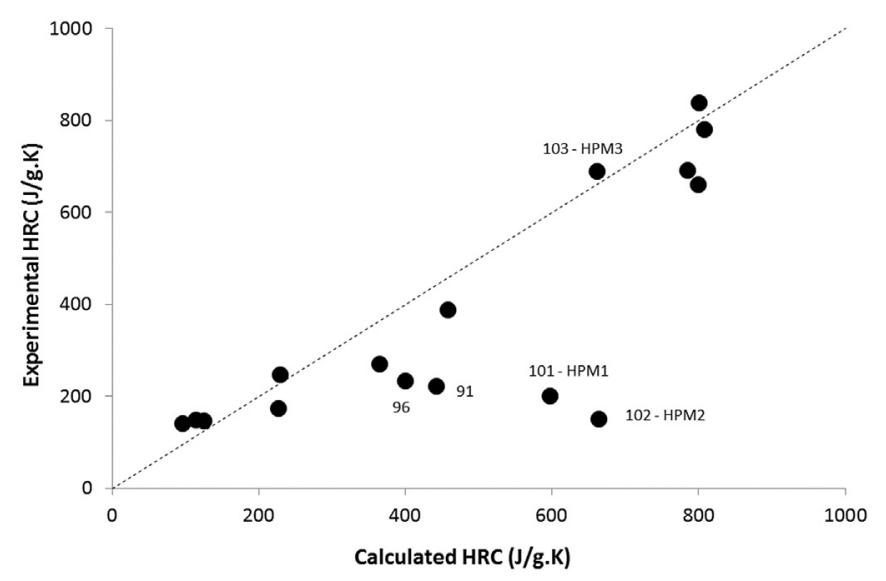

Fig. 14. Experimental versus calculated HRC for 16 phosphonate-based polymers. environment. This effect may be related to the higher thermal stability of the phenyl group.

\subsection{Contributions to THR: second database}

A second database with a reduced number of groups has been generated for the calculation of THR. Only 15 groups were considered. For example $\mathrm{C}, \mathrm{CH}, \mathrm{CH}_{2}$ and $\mathrm{CH}_{3}$ groups are collected. Similarly all $\mathrm{COO}$ groups (ester, acetate, acrylate and carboxylic acid) and most of halogenated groups are grouped together. Fig. 15 shows the calculated THR obtained with this second database. It is obvious that the correlation between the calculated and experimental THR remains very satisfying.

\section{Conclusions}

This work proposes a new database of group contributions using a step-by-step method. Some guidelines were developed for the choice of fragment groups. Considering all the polymers studied (excluding 8 exceptions) THR and HRC can be estimated with a mean error of only $16 \%$ and $28 \%$ from a database of 31 groups. In particular, THR can be estimated with good accuracy from only 15 groups for all polymers without noticeable exception.

The groups can be compared to identify those exhibiting the lowest contributions to THR and/or HRC. Such an approach also allows an assessment of the consistency of the proposed model.

Some polymers exhibit HRC much lower or higher than the calculated ones and can be considered as exceptions. Such a significant difference between experimental and calculated values permits the identification of some interesting structures or functional groups. In particular a specific structure of some polyesters exhibiting a $\mathrm{CH}_{3}$ group in alpha position with respect to the oxygen atom of the ester group appears to be significantly detrimental and leads to a very high HRC. A method for the calculation of the contribution of the phosphonate group has been proposed since this group seems to interact with its chemical environment in many cases. Consequently, some phosphonate-based polymers exhibit lower HRC than expected and this observation makes easier the identification of these interactions.

We hope that this work represents a major step towards the development of a method which will permit the prediction of the flame retardancy properties of macromolecular structures.

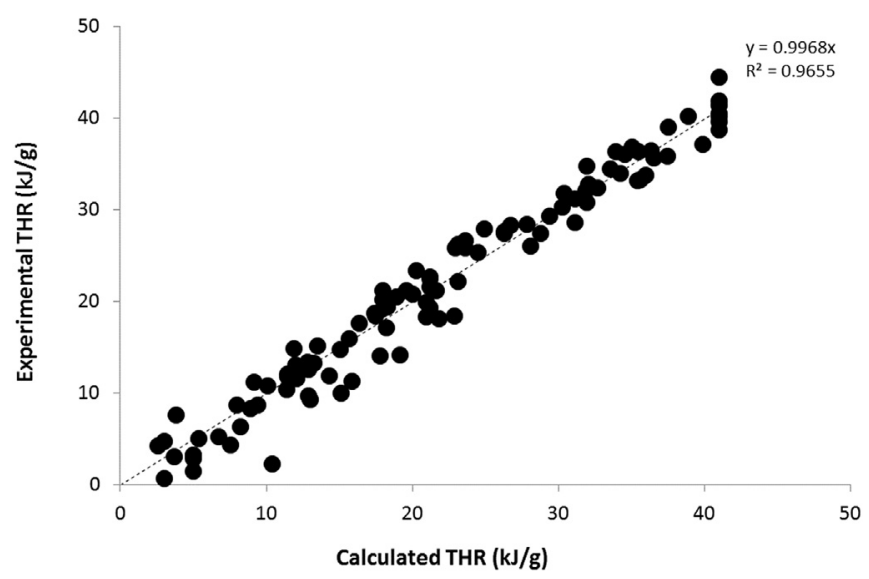

Fig. 15. Experimental versus calculated THR of 107 polymers according to the second database. 


\section{References}

[1] J.M. Raquez, M. Deléglise, M.F. Lacrampe, P. Krawczak, Thermosetting (bio) materials derived from renewable resources: a critical review,, Prog. Polym. Sci. 35 (2010) 487-509.

[2] L. Fertier, H. Koleilat, M. Stemmelen, O. Giani, C. Joly-Duhamel, V. Lapinte J.J. Robin, The use of renewable feedstock in UV-curable materials - a new age for polymers and green chemistry, Prog. Polym. Sci. 38 (2013) 932-962.

[3] F. Lichtenthaler, S. Peters, Carbohydrates as green raw materials for the chemical industry, C. R. Chimie 7 (2004) 65-90.

[4] M. Fache, R. Ménard, C. Negrell, S. Caillol, N. Illy, G. David, Phosphorylation of bio-based compounds: state of the art, Polym. Chem. 6 (2015) 6257-6291.

[5] D.W. Van Krevelen, Properties of Polymers, Elsevier, Amsterdam, 1990, pp. $627-653$.

[6] R.E. Lyon, M.T. Takemori, N. Safronova, S.I. Stoliarov, R.N. Walters, A molecular basis for polymer flammability, Polymer 50 (2009) 2608-2617.

[7] N. Walters, R.E. Lyon, Molar group contributions to polymer flammability, J. Appl. Polym. Sci. 87 (2003) 548-563.

[8] R. Sonnier, L. Ferry, C. Longuet, F. Laoutid, B. Friederich, A. Laachachi, J.M. Lopez-Cuesta, Combining cone calorimeter and PCFC to determine the mode of action of flame-retardant additives, Polym. Adv. Technol. 22 (2011) 1091-1099.

[9] R. Lyon, R. Walters, S. Stoliarov, Screening flame retardants for plastics using microscale combustion calorimetry, Polym. Eng. Sci. 47 (2007) 1501-1510.

[10] R. Lyon, N. Safronava, J. Quintiere, S. Stoliarov, R. Walters, S. Crowley, Material properties and fire test results, Fire Mater. 38 (2014) 264-278.

[11] R. Sonnier, C. Negrell-Guirao, H. Vahabi, B. Otazaghine, G. David, J.M. LopezCuesta, Relationships between the molecular structure and the flammability of polymers: study of phosphonate functions using microscale combustion calorimeter, Polymer 53 (2012) 1258-1266.

[12] H. Vahabi, L. Ferry, C. Longuet, R. Sonnier, C. Negrell-Guirao, G. David, J.M. Lopez-Cuesta, Theoretical and empirical approaches to understanding the effect of phosphonate groups on the thermal degradation for two chemically modified PMMA, Eur. Polym. J. 48 (2012) 604-612.

[13] ASTM D7309-13, Standard Test Method for Determining Flammability Characteristics of Plastics and Other Solid Materials Using Microscale Combustion Calorimetry, Method A, American Society for Testing and Materials, West Conshocken, PA, 2013.

[14] H.B. Chen, X. Dong, D. Schiraldi, L. Chen, D.Y. Wang, Y.Z. Wang, Phosphoruscontaining poly(trimethylene terephthalate) derived from 2-(6-oxido-6Hdibenz(c,e)(1,2)oxaphosphorin-6-yl)- 1,4-hydroxyethoxy phenylene: Synthesis, thermal degradation, combustion and pyrolysis behavior, J. Anal. Appl. Pyrolysis 99 (2013) 40-48.

[15] M. Shabanian, N. Nemat Basaki, H. Khonakdar, S.H. Jafari, K. Hedayati, U. Wagenknecht, Novel nanocomposites consisting of a semi-crystalline polyamide and $\mathrm{Mg}-\mathrm{Al} \mathrm{LDH}$ : morphology, thermal properties and flame retardancy, Appl. Clay Sci. 90 (2014) 101-108.

[16] A. Dumitrascu, B. Howell, Flame retardant polymeric materials achieved by incorporation of styrene monomers containing both nitrogen and phosphorus, Polym. Degrad. Stab. 97 (2012) 2611-2618.

[17] C. Huggett, Estimation of rate of heat release by means of oxygen consumption measurements, Fire Mater. 4 (1980) 61-65.

[18] R. Walters, N. Safronava, R. Lyon, A microscale combustion calorimeter study of gas phase combustion of polymers, Combust. Flame 162 (2015) 855-863.

[19] R. Sonnier, G. Dorez, H. Vahabi, C. Longuet, L. Ferry, FTIR-PCFC coupling: A new method for studying the combustion of polymers, Combust. Flame 161 (2014) 1398-1407. 